\title{
Consent for the discontinuation of life-prolonging treatment in cancer patients: a retrospective comparative analysis before and after the enforcement of the Life Extension Medical Decision law
}

\section{YuJin Chung}

Department of Emergency Medicine, Yonsei University College of Medicine

JinHo Beom ( $\square$ wangtiger@yuhs.ac )

Department of Emergency Medicine, Yonsei University College of Medicine

JiEun Lee

Department of Emergency Medicine, Yonsei University College of Medicine Incheol Park

Department of Emergency Medicine, Yonsei University College of Medicine Junho Cho

Department of Emergency Medicine, Yonsei University College of Medicine

\section{Research Article}

Keywords: Life Extension Medical Decision law, length of hospital stay, cardiopulmonary 4 resuscitation, intubation, continuous renal replacement therapy, 73 intensive care unit

Posted Date: December 18th, 2020

DOI: https://doi.org/10.21203/rs.3.rs-118257/v1

License: (c) (1) This work is licensed under a Creative Commons Attribution 4.0 International License. Read Full License 
1 Consent for the discontinuation of life-prolonging treatment in cancer patients: a retrospective

2 comparative analysis before and after the enforcement of the Life Extension Medical Decision

3 law

4

$5 \quad$ Yu Jin Chunga

6 aDepartment of Emergency Medicine, Yonsei University College of Medicine, Seoul, Republic of

$7 \quad$ Korea

8 Tel: $(+82)-2-2228-2460$

9 Fax: (+82)-2-2227-7908

10 E-mail: atruedreamerx3@yuhs.ac

12 Incheol Park ${ }^{\mathrm{a}}$

13 Department of Emergency Medicine, Yonsei University College of Medicine, Seoul, Republic of

14 Korea

15 Tel: (+82)-2-2228-2460

16 Fax: $(+82)-2-2227-7908$

17 E-mail: INCHEOL@yuhs.ac

18

19 Junho Cho

20 Department of Emergency Medicine, Yonsei University College of Medicine, Seoul, Republic of

$21 \quad$ Korea

22 Tel: (+82)-2-2228-2460

23 Fax: (+82)-2-2227-7908

24 E-mail: EMJH@yuhs.ac 
*Corresponding authors:

27 Jin Ho Beom

28 Department of Emergency Medicine, Yonsei University College of Medicine 50 Yonsei-ro,

29 Seodaemun-gu 120-752, Seoul, Republic of Korea

30 Tel: $(+82)-2-2228-2460$

31 Fax: (+82)-2-2227-7908

32 E-mail: wangtiger@yuhs.ac

33

$34 \quad$ Ji Eun Lee

35 Department of Emergency Medicine, Yonsei University College of Medicine 50 Yonsei-ro,

36 Seodaemun-gu 120-752, Seoul, Republic of Korea

37 Tel: (+82)-2-2228-2460

38 Fax: $(+82)-2-2227-7908$

39 Email: jieun920733@gmail.com

40

42 Abstract

\section{Background}

44 The Life Extension Medical Decision law enacted on February 4, 2018 in South Korea was the first to 45 consider the suspension of nonsensical life-prolonging treatment, and its enactment raised big controversy in Korean society. However, there is no study on whether the actual life-prolonging

47 treatment for patients has decreased after enforcing the law. This study aimed to compare the 48 provision of patient consent before and after the enforcement of the law among cancer patients who 
visited a tertiary university hospital's emergency room to understand the effects of the law on cancer patients' clinical care.

\section{Methods}

This retrospective single cohort study included advanced cancer patients over 19 years of age who visited the emergency room at a tertiary university hospital. The two study periods were as follows: from February 2017 to January 2018 (before) and from May 2018 to April 2019 (after). The primary outcome was the average length of hospital stay. The consent rate for cardiopulmonary resuscitation (CPR), intubation, continuous renal replacement therapy (CRRT), and intensive care unit (ICU) admission were the secondary outcomes.

\section{Results}

The average length of hospital stay decreased after the law was enforced, from 4 days to 2 days ( $\mathrm{p}=$ 0.001). The rates of direct transfers to secondary and nursing hospitals increased from $8.2 \%$ to $21.2 \%$ $(p=0.001)$ and from $1.0 \%$ to $9.7 \%$, respectively $(p<0.001)$. The rate of provision of consent for admission to the ICU decreased from $6.7 \%$ to $2.3 \%(\mathrm{p}=0.032)$. For CPR and CRRT, the rate of provision of consent decreased from $1.0 \%$ to $0.0 \%$ and from $13.9 \%$ to $8.8 \%$, respectively, but the differences were not significant $(\mathrm{p}=0.226$ and $\mathrm{p}=0.109$, respectively).

\section{Conclusion}

According to previous research, for patients wishing only conservative treatment, the reduction in hospital stays at tertiary hospitals ultimately reduces the physical, emotional, financial burdens and also improves the quality of end-of-life at home or in a hospice facility. In this context, this research ultimately show that the purpose of the LEMD law has been achieved. Further research in several hospitals including those patients who completed the consent after hospitalization is needed to generalize the clinical implication of the LEMD law.

Keywords: Life Extension Medical Decision law, length of hospital stay, cardiopulmonary 
73 resuscitation, intubation, continuous renal replacement therapy, intensive care unit 


\section{Background}

Cancer is one of the three leading causes of death in South Korea, with more than 210,000 newly diagnosed cases every year $(1,2)$. In 2007,79 million people died from cancer worldwide, and this number is expected to increase by about 45\%, with 115 million deaths in 2030 (3). The death burden due to cancer is heavy despite early diagnosis and aggressive treatment approaches (4). Cancer patients receive rigorous chemotherapy and thus, incur high treatments costs with longer than average hospital stays compared to patients with other illnesses (5). Therefore, it is important for cancer patients to decide their own direction of treatment, considering an improved quality of life and how they wish to spend the rest of it. That is, patients have the right to refuse nonsensical life-prolonging treatments, and such decisions should be made after thorough discussions between the patient, their family, and the medical professionals involved. In addition, the suspension of life-prolonging treatment must be guaranteed by an unbiased social system in consideration of the relevant ethical aspects.

However, in practice, it is rare that patients themselves decide to refuse life-sustaining treatment in the Korea's medical field, as in most cases, only the patient's family and medical professionals make this decision without sufficient discussion (6). Furthermore, in South Korea, the legal system concerning life-prolonging medical care has been incompetent in respecting the decision-making rights of patients.

Consequently, the Life Extension Medical Decision (LEMD) law, regarding the decisions on hospice care, palliative care, and life-prolonging medical care for patients close to death, was enforced on February 4, 2018, as an institutional measure to respect the dignity and rights of patients in South Korea (7). It provides legal provisions describing the criteria, conditions, and methods for discontinuing nonsensical life-prolonging care. The enforcement of this law resulted in a big controversy in the Korean society as this law respects the patient's right to self-determination, and allows all patients to end their lives comfortably while maintaining human dignity. 
100

101

102

103

104

105

106

107

108

109

110

111

112

113

Since the value of a patient's life is influenced by social consensus, which differs by culture, regulations related to life-prolonging medical care differ from country to country. A similar law was passed in the United States. In 1976, The Natural Death Act was passed in California, United States, and it was the first law to legally consider a patient's letter of intent to discontinue medical care (8). In addition, the Patient Self-Determination Act was passed in 1990, respecting patients' decisions and allowing them the independence to refuse treatment. According to a survey from 10 states in the United States, after the enactment of the self-determination law, the number of do-not-resuscitate (DNR) cases increased from $4.2 \%$ in 1990 to $13.3 \%$ in 1992, and the proportion of DNR orders increased from $31.1 \%$ to $51.5 \%$ (9).

Therefore, even in South Korea, with advent of the LEMD law, changes such as a decrease in lifeprolonging aggressive treatments and an increase in DNR documentations are expected. It is essential to comparatively analyze the type of changes observed in response to the enactment of this law in clinical practice. For instance, previous studies have shown that terminal cancer patients account for the highest proportion of patients receiving life-prolonging medical care (33.2\%); therefore, analyzing the influence of the enactment of the LEMD law on the use of life-prolonging treatments in advanced cancer patients would have significant implications in the clinical setting (10).

However, no study has been conducted on whether LEMD has practical effectiveness than the DNR. Therefore, in this study, we aimed to compare the relevant parameters such as the average length of hospital stay, consent rate of cardiopulmonary resuscitation (CPR), intubation, continuous renal replacement therapy (CRRT), and intensive care unit (ICU) admission, the rate of survival to discharge before and after the enforcement of the LEMD law in advanced cancer patients who visited the emergency room (ER) of a tertiary university hospital to implicate the effect of the law on cacner patients. 
Methods

\section{Study design}

This retrospective single cohort study was conducted at a tertiary university hospital. To compare the effects of the LEMD law, the periods of 1 year before and after enforcement were set as the target research periods, and the period of 3 months immediately after the enforcement of the law was considered as the adaptation period and thus, excluded from the study. Therefore, the two final study periods were as follows: from February 2017 to January 2018 and from May 2018 to April 2019.

Primary comparisons were made between these two study periods. The patients in each period were divided into two groups: one group included patients with a signed DNR or a life-sustaining treatment plan before their visit to the ER and the other included patients who prepared their DNR or lifesustaining treatment plan during their ER visit.

The study data were collected using the Severance Clinical Research Analysis Portal, the clinical data search system used by the hospital, and approved by the Institutional Review Board of Yonsei University Health System (approval number 4-2020-0630). This study was conducted in compliance with the Declaration of Helsinki, and the need for informed consent was waived due to the study's retrospective design.

\section{Participants}

Advanced cancer patients of over 19 years of age with stage IV or metastatic cancer who visited the ER of Severance Hospital during the study periods were included in this study.

Overall, the analyzed subjects included the following: (1) patients who visited the ER between February 2017 and January 2018, before the enforcement of the law, with a signed DNR obtained prior to the ER visit or those who prepared their DNR letters during their ER visit and (2) patients who visited the ER between May 2018 and April 2019, after the enforcement of the law, with advance directives prepared beforehand or those who prepared their life-sustaining treatment plans during the 
ER visit. If a contract was created but lacked the specific classification and accurate information, the corresponding patients were excluded from the study.

\section{Outcomes}

We investigated the length of hospital stay as the primary outcome.. In addition, CPR, intubation, CRRT, and ICU admissions were considered as secondary outcomes, to confirm whether the rate of aggressive treatments actually reduced with the enactment of the law. Furthermore, variables such as the time taken from reception to the completion of DNR orders or a life-sustaining treatment plan, time spent in the ER, transfer to nursing hospitals, ER mortality rate, and medical expenses were also analyzed.

1. Provision of do-not-resuscitate orders before the enforcement of the Life Extension Medical Decision law

DNR orders enforce the abanding of resuscitation attempts in patients with no prospect of resuscitation especially in patients with predicted cardiac arrest (11). This document has an arbitrary format used widely by medical institutions in clinical practice; however, the subject and format are not universal.

2. Provision of advance directives after the enforcement of the Life Extension Medical Decision law

Any adult 19 years of age or above can document his or her intention for life-sustaining treatment and hospice directly in preparation for the case where the person becomes a patient at the end stage of life in the future. The document prepared for this purpose is called the advance directive on lifesustaining treatment, and should be created after receiving sufficient explanation through the Registry Agencies for Advance Directives designated by the Ministry of Health and Welfare. The legal validity of the created and registered advance directives can be recognized only when they are kept in the database of life-sustaining treatment information processing system (7). 
3. Provision of a life-sustaining treatment plan after the enforcement of the Life Extension Medical Decision law

According to the decision of the terminally ill patient, the doctor-in-charge plans and documents the decisions related to the patient's life-sustaining medical treatment and hospice care (7), and the procedure involved in this process is shown in Fig. 1 (12).

\section{Statistical analysis}

The collected data were analyzed using the SAS software (version 9.4, SAS Inc., Cary, NC, USA). All continuous variables did not satisfy the normality assumption; thus, the variables were analyzed using the Wilcoxon rank-sum test and results were presented as medians (Q1, Q3). Categorical variables were analyzed using the chi-square test (Fisher's exact test) and presented as counts (\%). The Monte Carlo estimation method was used to accurately determine the location of the primary cancer. A p-value $<0.05$ was considered significant.

\section{Results}

During the study period, a total of 1,443 patients with stage IV advanced cancer or metastatic cancer were admitted to the hospital's ER. Overall, 433 and 1,010 patients visited the hospital before (February 2017-January 2018) and after (May 2018-April 2019) the enforcement of the LEMD law, respectively. Prior to the enforcement, 197 patients had written consent letters in advance or planned their treatment plans in the ER, while after the enforcement of the law, 220 people had advance directives beforehand or planned their treatment plans in the ER. Of these, five patients (two before and three after the enforcement) were excluded from the study due to incomplete information on the forms. Finally, 195 patients presenting before and 217 patients presenting after the enforcement were included as subjects of this study. Among these, 20 patients had obtained DNR orders in advance before the enforcement, and 78 patients had advance directives after the enforcement of the law. The 
number of patients who filled out their DNR consent form in the ER was 175, and 139 patients wrote their life-sustaining plan in the ER (Fig. 2).

After the LEMD law was enforced, the average time taken to prepare a patient consent letter was reduced to 232 minutes from 273 minutes ( $p=0.031$ ); conversely, the time spent in the ER increased from 817 minutes to 1,195 minutes $(p=0.006)$. The length of stay in the hospital decreased from 4 days to 2 days $(p=0.001)$, along with a decrease in average medical expenses $(p=0.008)$. Furthermore, the rate of direct transfers to secondary hospitals from the ER increased from $8.2 \%$ to $21.2 \%$ $(\mathrm{p}=0.001)$, and that of transfers to nursing hospitals increased from $1.0 \%$ to $9.7 \%(\mathrm{p}<0.001)$.

In addition, the rate of provision of consent for admission to the ICU decreased from $6.7 \%$ before the enforcement to $2.3 \%$ after the enforcement $(\mathrm{p}=0.032)$. In the case of CPR and CRRT, the rates of provision of consent decreased from $1.0 \%$ to $0.0 \%$ and from $13.9 \%$ to $8.8 \%$, respectively, but the difference was not significant ( $\mathrm{p}=0.226$ and $\mathrm{p}=0.109$, respectively). After the enforcement of the law, a larger number of patients were found to survive until discharge $(\mathrm{p}=0.001)$ (Table 1).

On comparing only those patients who created the DNR order or life-sustaining treatment plan in the ER, it was found that the average time taken from reception to creating the consent letter was 296 minutes before the enforcement, while the same task took significantly longer (466 minutes) after the enforcement $(\mathrm{p}<0.001)$. However, consistent with the results of the overall comparison, the average time spent in the ER increased from 864 minutes before the enforcement to 1,391 minutes after the enforcement ( $p=0.003$ ), and the length of hospital stay decreased from 4 days to 2 days $(p=0.001)$. The rates of direct transfers to secondary and tertiary hospitals, and nursing hospitals from the ER also increased in the period after the enforcement from $9.1 \%$ to $20.1 \%$, and from $1.1 \%$ to $10.1 \%$, respectively ( $p=0.005, p=0.001$, respectively). The proportion of patient deaths in the ER decreased from $88.6 \%$ to $80.6 \%$ after the law was implemented $(\mathrm{p}=0.049)$.

The percentage of aggressive treatments or procedures specified in the DNR order or life-sustaining plan decreased after the enforcement of the law. The rates of CPR, intubation, and CRRT decreased 
from $1.1 \%$ to $0.0 \%$, from $5.1 \%$ to $4.4 \%$, and from $1.1 \%$ to $0.0 \%$, respectively, but the decreases were not significant $(\mathrm{p}=0.506, \mathrm{p}=0.755$, and $\mathrm{p}=0.506$, respectively). However, there was a significant reduction in the percentage of ICU admissions from $6.9 \%$ to $1.5 \%(\mathrm{p}=0.026)$. When consent was obtained in the ER, there was no significant difference between the DNR and life-prolonging groups with respect to the rate of survival to discharge from the hospital $(\mathrm{p}=0.505)$ (Table 2).

The following two groups were compared: previously completed DNR and previously completed life-sustaining medical intention form. We established that the time spent in the ER increased from 510.5 minutes before the enforcement to 970.5 minutes after the enforcement $(p=0.042)$. Contrastingly, the average length of hospital stay decreased from 5.5 days to 2 days ( $\mathrm{p}=0.061$ ), along with an insignificant reduction in the overall average medical cost $(\mathrm{p}=0.133)$. The rate of transfers from the ER to other hospitals increased from $0.0 \%$ to $23.1 \%(\mathrm{p}=0.020)$. Lastly, the rate of survival to discharge showed a significant increase after the enforcement of the law $(p=0.001)$ (Table 3$)$. Since the patients in this comparative analysis had prepared their consent forms in advance, the time taken to complete the consent forms was not evaluated in this sub-analysis.

\section{Discussion}

On February 4, 2018, the "Act on Hospice, Palliative Care, and Life-sustaining Health Care Decisions for Patients on End of Life (Life Extension Medical Decision Law)" came into force in South Korea (7). This was the first law to consider the suspension of nonsensical life-prolonging medical care, which raised a big issue both in the medical field and in the social community.

We demonstrated that before the law was enforced, the time taken to obtain consent for preparing a life-sustaining treatment plan was longer than the time taken from ER admission to finalization of the DNR order. Additionally, the time spent in the ER was longer after the enforcement of the law. In contrast, the percentage of transfers to other hospitals increased and the length of hospital stay decreased after the law was enforced. There were no significant differences in the rates of most of the classified aggressive procedures before and after enforcement; however, the provision of consent for 
admission to the ICU decreased after enforcement. The rate of survival to discharge was particularly high in the group of patients who had completed a consent form before the ER visit.

The time from ER registration to signing the consent form was longer after the enforcement of the law, and this can be attributed to the peculiarity of the legal system. As shown in Fig. 1, if a patient who has not indicated an intention to discontinue life-prolonging treatment in advance is unconscious and cannot confirm their intention, a decision can be made only after all of the family members come to a unanimous agreement. In the period following the enforcement, not many patients had prepared such documents in advance, and many severely ill patients were unconscious at presentation; thus, it took a long time for all family members to come to a unanimous decision. However, after a certain period of time, even in the absence of an official life-sustaining treatment plan, the patient's attending physician usually documents medical records about their will indicating an intention to discontinue life-prolonging medical treatment. Thus, it was possible to discontinue life-prolonging treatment at a relatively early stage with a decision statement from only two family members. If the time to finalize consent is prolonged, the length of ER stay also increases, which may cause overcrowding in the emergency care center. This clearly indicates the need for a simplified procedure for preparing a lifesustaining care scheme.

In this study, the increase in the length of ER stay can be understood in relation to the increase in the rate of direct transfer from the ER to other hospitals. Before the LEMD law was implemented, the rate of transfer to other hospitals was only $8.2 \%$ and that of transfer to a nursing hospital was $1.0 \%$, but the corresponding rates increased to $21.2 \%$ and $9.7 \%$, respectively, after implementation (Table 1 ). Considering that the length of ER stay has been extended in the same way in the patient group who wrote the life-sustaining treatment plan in advance, the longer stay in the ER is a separate issue from the time it takes to complete the consent form. It is most likely because the number of direct transfers to other hospitals, especially nursing hospitals has increased. In South Korea, transfer to nursing hospitals is mostly possible only during regular consultation sessions, and patients have to wait until regular hours; therefore, selecting a nursing hospital utilizes an inordinate amount of time. Even 
though direct transfer from the ER to a nursing hospital is beneficial for conservative management, the resulting increase in the length of hospital stay causes simultaneous overcrowding in the ER. This can lead to a reduction in the ER's capacity to accommodate patients, disruption of medical practice for those in urgent need of treatments, and an increase in the mortality rate (13). An earlier study suggested the use of alternative care facilities as one of the ways to resolve ER overcrowding. This has been shown to not only reduce waiting times and medical expenses but also improve patient outcomes and satisfaction with the medical staff (13). In other words, rather than staying in the ER while waiting for hospitalization or transfer to other hospitals, admission to the hospice ward could be a good option for patients who have already written a life-sustaining treatment plan; their transfer to palliative care hospitals can be considered later. However, in Severance Hospital, we have no choice but to keep patients waiting in the ER due to the absence of a hospice ward; this area has scope for further improvement.

Contrary to the time spent in the ER, the number of patients discharged to nursing hospitals for conservative treatment or home care will increase and the total length of hospital stay will be shortened if the number of patients who prepare life-sustaining plans increase. This was consistent with the results from our study. As the disease progresses, the hospitalization rate of patients increases exponentially, which leads to spending more time in the hospital during the last six months of life; this is especially true for cancer patients (14). In the case of cancer patients, nutrition support or pain control is often the most common reason for hospital admission, in addition to chemotherapy. However, these types of symptom control treatments can be adequately provided in secondary and nursing hospitals. From a medical professional's point of view, hospital beds must be used for patients who absolutely need treatment in tertiary hospitals, but this is not the case in real-world practice as patients and their families demand hospitalization at a tertiary university hospital even for receiving chemotherapy or supportive care. Of course, such requests are rational considering the psychological reassurance received by patients and their families on admission to a hospital equipped with doctors and facilities competent enough to cope with emergencies; however, admission to a tertiary university 
hospital solely for receiving supportive care will deprive other cancer patients who require more aggressive and urgent treatment. The problem is even more concerning in hospitals that do not have a hospice ward. A study showed that receiving specialized treatment in the ambulatory care sector is associated with reduced bed utilization and a reduced need for hospitalization, especially in advanced cancer patients (14). Therefore, if patients who have a life-sustaining treatment plan prepared in advance utilize a nursing hospital or a primary medical institution, the frequency of unplanned hospitalizations to a higher-level hospital can be reduced, and other patients can avail treatment opportunities. Furthermore, from the patient's point of view, receiving treatment at a specialized facility with caregivers who can provide focused hospice care can reduce emotional and mental stress. As mentioned above, this could potentially be of great help in improving the patient's quality of life. Therefore, it can be inferred that the reduction in length of hospital stay is an important consequence of the enactment of the LEMD law and fulfills the purpose of the enforcement of this law.

When the patient fills out the life-sustaining plan document, the patient may refuse all ultimate treatments, but with the patient's will, some aggressive treatment may be sought later. In this study, as the LEMD law was implemented, a difference was expected in the provision of consent for each aggressive treatment before and after implementation. However, this study showed that there was no difference in the provision of consent for CPR, intubation, and CRRT, although the provision of consent for admission to the ICU showed differences. The results of previous international studies have revealed that even if a life-sustaining treatment plan is prepared, the treatment goals widely vary, subjectively reflecting each patient's will. For example, patients receiving conservative treatment only and patients receiving some restrictive treatment may not be revived but may receive all aggressive treatments $(15,16)$; however, the procedures described in the domestic life-sustaining treatment plan include CPR, intubation, CRRT, and ICU admission, and each of them is interconnected and related to resuscitation. Furthermore, in critical situations, it is not easy to choose only one or two of these aggressive treatment approaches. Besides, there are differences in the scope of treatment that patients want to receive depending on the timing of preparation of the life-sustaining care plan (17). For 
instance, if a patient visits the ER and prepares a life-sustaining plan, there will not be enough time to think about how aggressive treatment to continue. Moreover, considering the situation in which a lifesustaining care plan is being prepared, it is conceivable that a plan prepared in the ER is intended for a patient who is no longer likely to be resuscitated or is dying. In such situations, it is virtually difficult to explain the aggressive treatments related to the patient's resuscitation to the patient's guardians in despair and select some of them. Additionally, even if the caregiver selects only some of the listed procedures, it may not make sense for the medical professionals to perform only some of those treatments for the aforementioned reasons. Therefore, it might be difficult to explain to the patients or caregivers that partially consenting to vigorous treatments might not be fruitful. Consequently, there seems to be no difference in the rate of aggressive procedures before and after the LEMD law was implemented.

The rate of survival to discharge were significantly higher in patients who had advance direcrtives before visiting the ER than in patients who wrote life sustaining treatment plan in the ER. This is proof that the patients who wrote the letter of intent for life-sustaining treatment in advance had time to ponder about the quality of their remaining life thoroughly. The preparation of a life-sustaining care plan enables patients to be discharged or transferred after recovering from their condition without the continuation of unwanted treatment, even if the patients are hospitalized unexpectedly. Earlier studies have also revealed that the preparation of a letter of intent for life-sustaining treatment in advance is associated with decreased hospital mortality and an increase in hospice use (18), which is equivalent to an increase in the rate of survival to discharge. Besides, one study found that patients receiving only limited treatment have shorter hospital stays, which increases the rate of discharge to hospice hospitals for conservative treatment (19). This study confirmed that the rate of survival to discharge significantly increased after the LEMD law was enforced, and patients were discharged to home, hospice, or long-term care facilities. The families of patients receiving hospice services were generally highly satisfied with the quality of care $(20,21)$, and the fact that patients can spend the end of their lives with their families significantly helps in improving the quality of end-of-life. In this 
study, it was demonstrated that patients who had written a letter of intent for life-sustaining treatment in advance wanted an improved quality of life at home or in a hospice facility rather than lifeprolonging treatment at a university hospital. Although the number of patients in this group was small and not significant, the reduction in the length of hospital stay by more than half can be considered a supporting result. Since the enactment of the LEMD law, more and more patients are writing their intentions and plans regarding life-sustaining treatment in advance; thus, it is necessary to improve the quality of medical services for patients receiving conservative treatment by activating domestic hospice programs in the future.

Previously, there was no legal system for the suspension of life-prolonging treatment, and thus, treatment for life extension continued regardless of the patient's will. Alternatively, in many cases in which the patient was on the verge of dying, their guardians fill out the DNR consent form, and the patients can die without receiving even non-aggressive treatment. Near the end-of-life, intensive care for patients who do not want active treatment imposes physical, emotional, and financial burdens $(22,23)$, which lead to a poor quality of life. Therefore, to improve the quality of life of patients with a short life expectancy, it is necessary to respect the freedom and will of patients who have prepared a life-sustaining treatment plan. This approach will also reduce unnecessary admissions to university hospitals, enabling the provision of high-quality treatment to patients who need aggressive treatments.

Although the number of patients who write their life-sustaining treatment plans in advance is increasing, there are still no studies comparing the effects of this law and DNR orders, a similar document used before the implementation of this law. Therefore, this study has a significant advantage in that it is the first to investigate the differences in the provision of consent for DNR orders before and after the enforcement of the LEMD law.

There are several limitations to this study. First, this study was conducted at one university hospital in South Korea, and thus, the results cannot be generalized to the entire country. In subsequent research, continuing the study in several other university hospitals will increase the reliability of the results and contribute to generalization. Second, as we only included those who prepared the life- 
sustaining treatment plan before ER presentation (outpatient/other institutions) and in the ER, patients who completed the document in the ward after admission through the ER were not included. In the follow-up study, it would be interesting to include those patients who completed the consent form in the ward after hospitalization. Thirdly, since the DNR consent format and the life-sustaining treatment plan format are different, some detailed procedures, even with slight differences, were excluded from the study.

\section{Conclusion}

This study aimed to compare the relevant parameters before and after the enforcement of the LEMD law to determine its clinical implications in South Korea. After the law was implemented, the average length of stay in the tertiary university hospital decreased for patients who prepared life-sustaining treatment plans in advance. Moreover, according to the law's purpose, the provision of consent for ICU admission for aggressive treatments decreased. For patients wishing only conservative treatment, the reduction in hospital stays at university hospitals ultimately reduces the physical, emotional, financial burdens and also improves the quality of end-of-life at home or in a hospice facility. The rates of provision of consent for CPR, intubation, and CRRT were not significantly different before and after enforcement. Because this study is conducted in the ER of one university hospital in South Korea, further research in several other hospitals including those patients who completed the consent form in the ward after hospitalization is needed to generalize the clinical implication of the LEMD law.

\section{List of abbreviations}

CPR Cardiopulmonary resuscitation

CRRT Continuous renal replacement therapy

DNR Do-not-resuscitate 
Emergency room

$400 \quad$ ICU

Intensive care unit

401

LEMD

Life Extension Medical Decision

402

403

404

405

\section{Declarations}

406

\section{Ethics approval and consent to participate}

407 The study data were collected using the Severance Clinical Research Analysis Portal, the clinical 408 data search system used by the hospital, and approved by the Institutional Review Board of Yonsei 409 University Health System (approval number 4-2020-0630). This study was conducted in compliance 410 with the Declaration of Helsinki, and the need for informed consent was waived due to the study's 411 retrospective design.

\section{Consent for publication}

413 Not applicable

$414 \quad$ Availability of data materials

415 The datasets used and/or analysed during the current study are available fromthe corresponding 416 author on reasonable request

\section{$417 \quad$ Competing interests}

418 The authors declare that they have no competing interests

\section{$419 \quad$ Funding}


$420 \quad$ Not applicable

$421 \quad$ Authors' contributions

422 All the authors contributed to the conceptualisation of this work. YJC, JHB designed the study. JEL

423 collected the data. YJC and JHB developed the data analysis strategy. YJC and JEL prepared the frst

424 draft of the manuscript. JHB commented. Revisions were made by YJC and all the other authors (YJC,

425 JHB, JEL) read and approved the fnal manuscript. ICP and JHC supervised the overall work.

$426 \quad$ Acknowledgments

$427 \quad$ Not applicable 


\section{References}

1. Statistics Korea. Cause of death statistics in 2018 [Internet]. Daejeon: Statistics Korea. 2018 [cited 2019 Sep 24]. Available from: http://kostat.go.kr/

2. Jung KW, Won YJ, Kong HJ, Lee ES. Prediction of Cancer Incidence and Mortality in Korea, 2018. Cancer Res Treat. 2018 Apr;50(2):317-23. doi: 10.4143/crt.2018.142.

3. Boyle P, Levin B. World cancer report 2008. Lyon: International Agency for Research on cancer; 2008.

4. Centers for Disease Control and Prevention. Cancer survivorship-United States, 1971-2001. MMWR Morb Mortal Wkly Rep. 2004 Jun;53(24):526-9.

5. Price RA, Stranges E, Elixhauser A. Cancer Hospitalizations for Adults, 2009: Statistical Brief \#125. 2012 Feb. In: Healthcare Cost and Utilization Project (HCUP) Statistical Briefs [Internet]. Rockville (MD): Agency for Healthcare Research and Quality (US); 2006 Feb. Available from: https://www.ncbi.nlm.nih.gov/books/NBK92614/

6. Heo DS. Patient Autonomy and Advance Directives in Korea. J Korean Med Assoc. 2009;52(9):865-70. doi: 10.5124/jkma.2009.52.9.865

7. Ministry of Government Legislation. Act on hospice and palliative care and decisions on lifesustaining treatment for patients at the end of life [Internet]. Sejong: Ministry of Government Legislation. 2016 [cited 2018 Jan 2]. Available from: http:// www.law.go.kr/법령/호스피스 - 완화의료및임종과정에있는환자 의연명의료결정에관한법률/(14013,20160203).

8. Wilkinson A, Wenger N, Shugarman LR. Literature review on advance directives. Washington, D.C.: U.S. Department of Health and Human Services; 2007.

9. Teno JM, Branco KJ, Mor V, Phillips CD, Hawes C, Morris J, et al. Changes in advance care planning in nursing homes before and after the patient Self-Determination Act: report of a 10state survey. J Am Geriatr Soc. 1997 Aug;45(8):939-44. doi: 10.1111/j.15325415.1997.tb02963.x.

10. Bioethics Policy Research Center. Survey on withdrawal of life-sustaining treatment and advanced directives. Seoul: Bio-ethics Policy Research Center; 2011.

11. Jeong SP, Yoon CJ, Oh JH, Yoon SY, Jang WJ, Lee HS. A retrospective review of the DoNot-Resuscitate patients. Journal of the Korean Society of Emergency Medicine. 
1998;9(2):271-6.

458

459

460

461

462

463

464

465

466

467

468

469

470

12. National Agency for Management of Life-Sustaining Treatment. Guidance on the lifesustaining treatment decision system (for medical institutions). 2019 Jun. Available from: https://www.lst.go.kr/

13. Yarmohammadian MH, Rezaei F, Haghshenas A, Tavakoli N. Overcrowding in emergency departments: A review of strategies to decrease future challenges. J Res Med Sci. 2017 Feb;22:23. doi: 10.4103/1735-1995.200277.

14. Huang J, Boyd C, Tyldesley S, Zhang-Salomons J, Groome PA, Mackillop WJ. Time spent in hospital in the last six months of life in patients who died of cancer in Ontario. J Clin Oncol. 2002 Mar;20(6):1584-92. doi: 10.1200/JCO.2002.20.6.1584.

15. Schmidt TA, Zive D, Fromme EK, Cook JN, Tolle SW. Physician orders for life-sustaining treatment (POLST): lessons learned from analysis of the Oregon POLST Registry. Resuscitation. 2014 Apr;85(4):480-5. doi: 10.1016/j.resuscitation.2013.11.027.

16. Brinkman-Stoppelenburg A, Rietjens JA, van der Heide A. The effects of advance care planning on end-of-life care: A systematic review. Palliat Med. 2014 Sep;28(8):1000-25. doi: $10.1177 / 0269216314526272$.

17. Zive DM, Fromme EK, Schmidt TA, Cook JN, Tolle SW. Timing POLST Form Completion by Cause of Death. J Pain and Symptom Management. 2015 Nov;50(5):650-8. doi: 10.1016/j.jpainsymman.2015.06.004.

18. Bischoff KE, Sudore R, Miao Y, Boscardin WJ, Smith AK. Advance Care Planning and the Quality of End-of-Life Care among Older Adults. J Am Geriatr Soc. 2013 Feb;61(2):209-14. doi: 10.1111/jgs. 12105.

19. Vranas KC, Lin AL, Zive D, Tolle SW, Halpern SD, Slatore CG, et al. The Association of Physician Orders for Life-Sustaining Treatment With Intensity of Treatment Among Patients Presenting to the Emergency Department. Ann Emerg Med. 2020 Feb;75(2):171-80. doi: 10.1016/j.annemergmed.2019.05.008.

20. Teno JM, Clarridge BR, Casey V, Welch LC, Wetle T, Shield R, et al. Family perspectives on end-of-life care at the last place of care. JAMA. 2004 Jan;291(1):88-93. doi: 10.1001/jama.291.1.88. 
486

487

488

489

490

491

492

493

494

495

496

497

498

499

500

501

502

503

504

505

506

507

508

509

510

511

512

09

10

21. Wright AA, Keating NL, Ayanian JZ, Chrischilles EA, Kahn KL, Ritchie CS, et al. Family Perspectives on Aggressive Cancer Care Near the End of Life. JAMA. 2016 Jan;315(3):28492. doi:10.1001/jama.2015.18604.

22. Lee RY, Brumback LC, Sathitratanacheewin S, Lober WB, Modes ME, Lynch YT, et al. Association of Physician Orders for Life-Sustaining Treatment With ICU Admission Among Patients Hospitalized Near the End of Life. JAMA. 2020;323(10):950-60. doi: 10.1001/jama.2019.22523.

23. Mack JW, Weeks JC, Wright AA, Block SD, Prigerson HG. Prigerson. End-of-Life Discussions, Goal Attainment, and Distress at the End of Life: Predictors and Outcomes of Receipt of Care Consistent With Preferences. J Clin Oncol. 2010 Mar;28(7):1203-8. doi: 10.1200/JCO.2009.25.4672.

4

9

\section{0}

1

2

3

4

505

06

07


513 Table 1. Comparison of parameters before and after the enforcement of the law

\begin{tabular}{|c|c|c|c|}
\hline \multirow[t]{2}{*}{ Variable } & \multicolumn{2}{|c|}{ Group } & \multirow[t]{2}{*}{$p$-value } \\
\hline & Before $(n=195)$ & After $(n=217)$ & \\
\hline $\begin{array}{l}\text { Time taken from reception to } \\
\text { obtaining written consent } \\
\text { (mins) }\end{array}$ & $273(117,501)$ & $232(0,683)$ & 0.031 \\
\hline Time spent in the ER (mins) & $817(447,1705)$ & $1,195(594,2151)$ & 0.006 \\
\hline Length of admission (days) & $4(1,10)$ & $2(0,8)$ & 0.001 \\
\hline Medical expenses (won) & $\begin{array}{c}3,718,989 \\
(1,776,908,6,629,026)\end{array}$ & $\begin{array}{c}2,691,195 \\
(1,356,584,5,347,890)\end{array}$ & 0.008 \\
\hline Type of visit & & & 0.860 \\
\hline Direct visit to the ER & $144(73.9)$ & $155(71.4)$ & \\
\hline $\begin{array}{ll} & \text { Transfer from } \\
& \text { another hospital } \\
& \text { Transfer from the } \\
\text { OPD } & \end{array}$ & $\begin{array}{l}46(23.6) \\
5(2.6)\end{array}$ & $\begin{array}{l}56(25.8) \\
6(2.8)\end{array}$ & \\
\hline Transfer from the ER & & & 0.001 \\
\hline Yes & $16(8.2)$ & $46(21.2)$ & \\
\hline No & $179(91.8)$ & $171(78.8)$ & \\
\hline $\begin{array}{l}\text { Transfer from the ER to a } \\
\text { nursing hospital }\end{array}$ & & & $<0.001$ \\
\hline Yes & $2(1.0)$ & $21(9.7)$ & \\
\hline No & $193(99.0)$ & $195(90.3)$ & \\
\hline Death in the ER & & & 0.363 \\
\hline Yes & $173(88.7)$ & $186(85.7)$ & \\
\hline No & $22(11.3)$ & $31(14.3)$ & \\
\hline Primary cancer & & & 0.599 \\
\hline Pancreatic cancer & $15(7.69)$ & $18(8.3)$ & \\
\hline Gastric cancer & $24(12.31)$ & $16(7.4)$ & \\
\hline $\begin{array}{l}\text { Head, neck, and oral } \\
\text { cancer }\end{array}$ & $6(3.08)$ & $8(3.7)$ & \\
\hline $\begin{array}{l}\text { Liver and intrahepatic } \\
\text { bile duct cancer }\end{array}$ & $25(12.8)$ & $37(17.1)$ & \\
\hline $\begin{array}{l}\text { Lung, tracheal, and } \\
\text { bronchial cancer }\end{array}$ & $47(24.1)$ & $46(21.2)$ & \\
\hline Hematologic cancer & $1(0.5)$ & $1(0.5)$ & \\
\hline Esophageal cancer & $2(1.0)$ & $3(1.4)$ & \\
\hline Colorectal cancer & $21(10.8)$ & $36(16.6)$ & \\
\hline Breast cancer & $19(9.7)$ & $14(6.5)$ & \\
\hline Prostatic cancer & $3(1.5)$ & $5(2.3)$ & \\
\hline $\begin{array}{l}\text { Uterus, ovarian, and } \\
\text { cervical cancer }\end{array}$ & $8(4.1)$ & $12(5.5)$ & \\
\hline
\end{tabular}




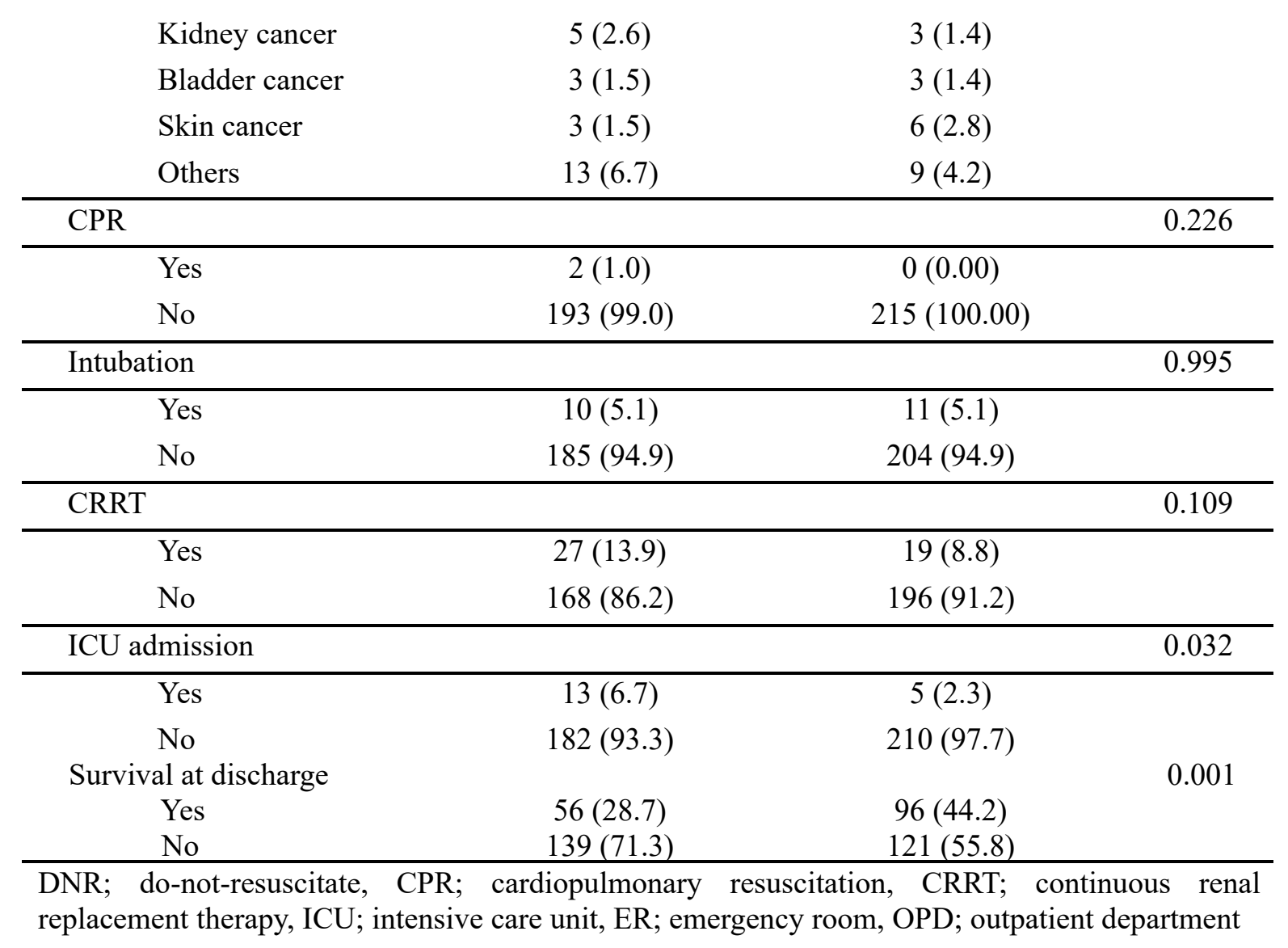


530 Table 2. Comparison of parameters when life-sustaining treatment plan or DNR consent form was 531 obtained in the ER

\begin{tabular}{|c|c|c|c|}
\hline \multirow[t]{2}{*}{ Variable } & \multicolumn{2}{|c|}{ Group } & \multirow[t]{2}{*}{$p$-value } \\
\hline & Before $(n=175)$ & After $(n=139)$ & \\
\hline $\begin{array}{l}\text { Time taken from reception to } \\
\text { obtaining written consent } \\
\text { (mins) }\end{array}$ & $296(155,532)$ & $466(245,963)$ & $<0.001$ \\
\hline Time spent in the ER (mins) & $864(479,1750)$ & $1,391(642,2,467)$ & 0.003 \\
\hline Length of admission (days) & $4(1,9)$ & $2(0,6)$ & 0.001 \\
\hline Medical expenses (won) & $\begin{array}{c}3,782,083 \\
(1,732,649,6,638,183)\end{array}$ & $\begin{array}{c}2,755,304 \\
(1,615,569,4,823,854)\end{array}$ & 0.076 \\
\hline Type of visit & & & 0.208 \\
\hline Direct visit to the ER & $134(76.6)$ & $94(67.6)$ & \\
\hline $\begin{array}{l}\text { Transfer from } \\
\text { another hospital }\end{array}$ & $36(20.6)$ & $40(28.8)$ & \\
\hline OPD Transfer from the & $5(2.9)$ & $5(3.6)$ & \\
\hline Transfer from the ER & & & 0.005 \\
\hline Yes & $16(9.1)$ & $28(20.1)$ & \\
\hline No & $159(90.9)$ & $111(79.9)$ & \\
\hline $\begin{array}{l}\text { Transfer from the ER to a } \\
\text { nursing hospital }\end{array}$ & & & 0.001 \\
\hline Yes & $2(1.1)$ & $14(10.1)$ & \\
\hline No & $173(98.9)$ & 125 (89.9) & \\
\hline Death in the ER & & & 0.049 \\
\hline Yes & $155(88.6)$ & $112(80.6)$ & \\
\hline No & $20(11.4)$ & $27(19.4)$ & \\
\hline Primary cancer & & & 0.712 \\
\hline Pancreatic cancer & $13(7.4)$ & $12(8.6)$ & \\
\hline Gastric cancer & $22(12.6)$ & $10(7.2)$ & \\
\hline $\begin{array}{l}\text { Head, neck, and oral } \\
\text { cancer }\end{array}$ & $5(2.9)$ & $4(2.9)$ & \\
\hline $\begin{array}{l}\text { Liver and intrahepatic } \\
\text { bile duct cancer }\end{array}$ & $19(10.9)$ & $21(15.1)$ & \\
\hline $\begin{array}{l}\text { Lung, tracheal, and } \\
\text { bronchial cancer }\end{array}$ & $45(25.7)$ & $34(24.5)$ & \\
\hline Hematologic cancer & $1(0.6)$ & $1(0.7)$ & \\
\hline Esophageal cancer & $1(0.6)$ & $3(2.2)$ & \\
\hline Colorectal cancer & $20(11.4)$ & $22(15.8)$ & \\
\hline Breast cancer & $16(9.1)$ & $10(7.2)$ & \\
\hline Prostatic cancer & $3(1.7)$ & $2(1.4)$ & \\
\hline
\end{tabular}




\begin{tabular}{|c|c|c|c|}
\hline $\begin{array}{l}\text { Uterus, ovarian, and } \\
\text { cervical cancer }\end{array}$ & $8(4.6)$ & $8(5.8)$ & \\
\hline Kidney cancer & $5(2.9)$ & $3(2.2)$ & \\
\hline Bladder cancer & $3(1.7)$ & $2(1.4)$ & \\
\hline Skin cancer & $3(1.7)$ & $4(2.9)$ & \\
\hline Others & $11(6.3)$ & $3(2.2)$ & \\
\hline CPR & & & 0.506 \\
\hline Yes & $2(1.1)$ & $0(0.0)$ & \\
\hline No & $173(98.9)$ & $137(100.0)$ & \\
\hline Intubation & & & 0.755 \\
\hline Yes & $9(5.1)$ & $6(4.4)$ & \\
\hline No & $166(94.9)$ & $131(95.6)$ & \\
\hline CRRT & & & 0.506 \\
\hline Yes & $2(1.1)$ & $0(0.0)$ & \\
\hline No & $173(98.9)$ & $137(100.0)$ & \\
\hline ICU admission & & & 0.026 \\
\hline Yes & $12(6.9)$ & $2(1.5)$ & \\
\hline No & $163(93.1)$ & $135(98.5)$ & \\
\hline Survival at discharge & & & 0.505 \\
\hline Yes & $53(30.3)$ & $47(33.8)$ & \\
\hline No & $122(69.7)$ & $92(66.2)$ & \\
\hline
\end{tabular}


547 Table 3. Comparison of parameters when the life-sustaining treatment plan or DNR consent form was 548 completed before visiting the ER

\begin{tabular}{|c|c|c|c|}
\hline \multirow[t]{2}{*}{ Variable } & \multicolumn{2}{|c|}{ Group } & \multirow[t]{2}{*}{$p$-value } \\
\hline & Before $(n=20)$ & After $(n=78)$ & \\
\hline Time spent in the ER (mins) & $510.5(349.5,1085)$ & $970.5(462,1615)$ & 0.042 \\
\hline Length of admission (days) & $5.5(3,10)$ & $2(0,10)$ & 0.061 \\
\hline Medical expenses (won) & $\begin{array}{l}3,593,733.5 \\
(2,439,355.5, \\
4,899,793.5) \\
\end{array}$ & $\begin{array}{c}2,167,290.5 \\
(961,601,6,025,705)\end{array}$ & 0.133 \\
\hline Type of visit & & & 0.025 \\
\hline Direct visit to the ER & $10(50.0)$ & $61(78.2)$ & \\
\hline $\begin{array}{l}\text { Transfer from } \\
\text { another hospital }\end{array}$ & $10(50.0)$ & $16(20.5)$ & \\
\hline Transfer from the & $0(0.0)$ & $1(1.3)$ & \\
\hline Transfer from the ER & & & 0.020 \\
\hline Yes & $0(0.0)$ & $18(23.1)$ & \\
\hline No & $20(100.0)$ & $60(76.9)$ & \\
\hline $\begin{array}{l}\text { Transfer from the ER to a } \\
\text { nursing hospital }\end{array}$ & & & 0.339 \\
\hline Yes & $0(0.0)$ & $7(9.1)$ & \\
\hline No & $20(100.0)$ & $70(90.9)$ & \\
\hline Death in the ER & & & 0.599 \\
\hline Yes & $18(90.0)$ & $74(94.9)$ & \\
\hline No & $2(10.0)$ & $4(5.1)$ & \\
\hline Primary cancer & & & 0.571 \\
\hline Pancreatic cancer & $2(10.0)$ & $6(7.7)$ & \\
\hline Gastric cancer & $2(10.0)$ & $6(7.7)$ & \\
\hline $\begin{array}{l}\text { Head, neck, and oral } \\
\text { cancer }\end{array}$ & $1(5.0)$ & $4(5.1)$ & \\
\hline $\begin{array}{l}\text { Liver and intrahepatic } \\
\text { bile duct cancer }\end{array}$ & $6(30.0)$ & $16(20.5)$ & \\
\hline $\begin{array}{l}\text { Lung, tracheal, and } \\
\text { bronchial cancer }\end{array}$ & $2(10.0)$ & $12(15.4)$ & \\
\hline Hematologic cancer & $0(0.0)$ & $0(0.0)$ & \\
\hline Esophageal cancer & $1(5.0)$ & $0(0.0)$ & \\
\hline Colorectal cancer & $1(5.0)$ & $14(18.0)$ & \\
\hline Breast cancer & $3(15.0)$ & $4(5.1)$ & \\
\hline Prostatic cancer & $0(0.0)$ & $3(3.9)$ & \\
\hline $\begin{array}{l}\text { Uterus, ovarian, and } \\
\text { cervical cancer }\end{array}$ & $0(0.0)$ & $4(5.1)$ & \\
\hline Kidney cancer & $0(0.0)$ & $0(0.0)$ & \\
\hline
\end{tabular}




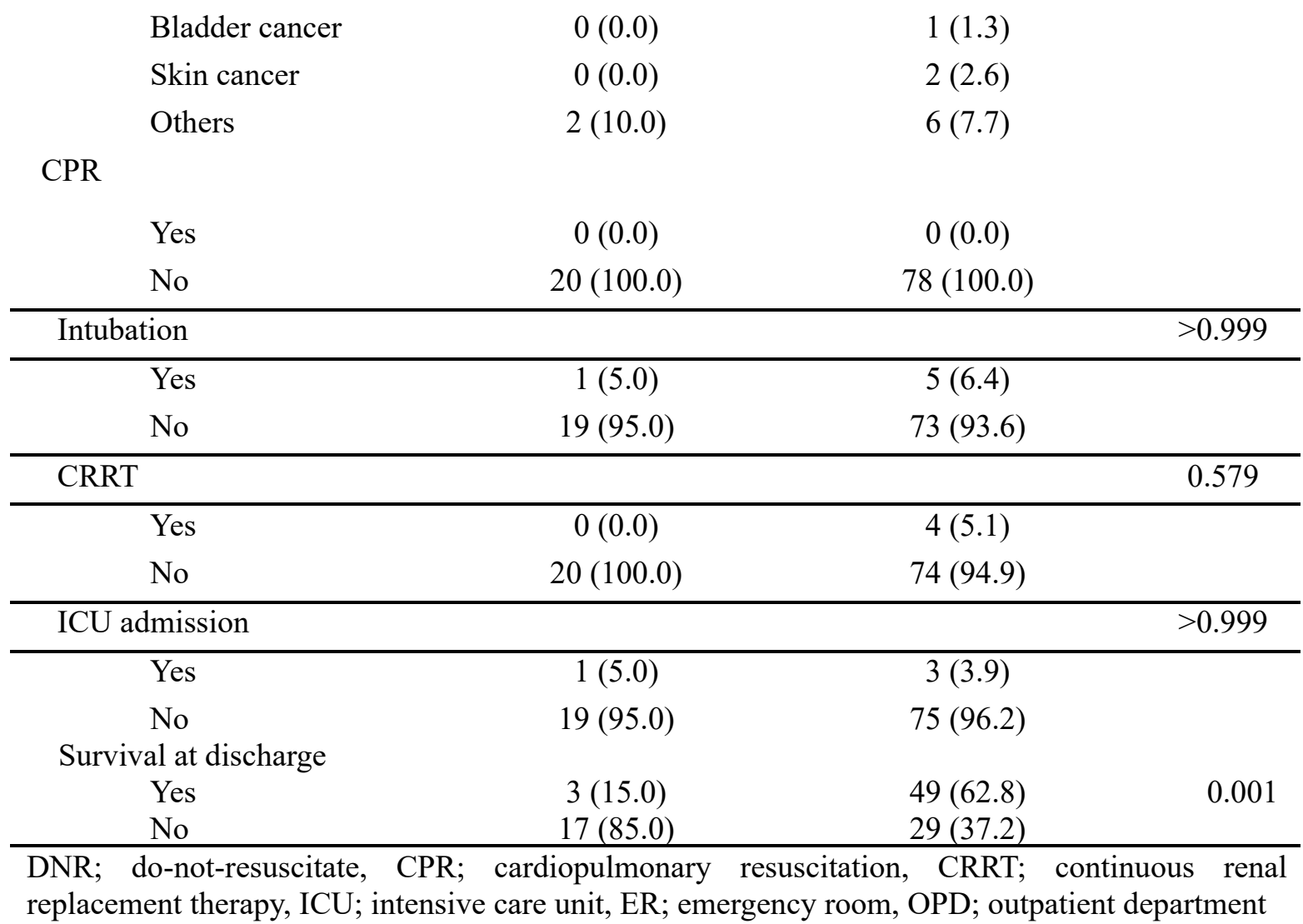




\section{Figure legends}

566 Fig. 1. Procedure of decision-making to discontinue life-prolonging care

567 Fig. 2. Flow diagram of patient eligibility

568 DNR; do-not-resuscitate, ER; emergency room, OPD; outpatient department 569

570 


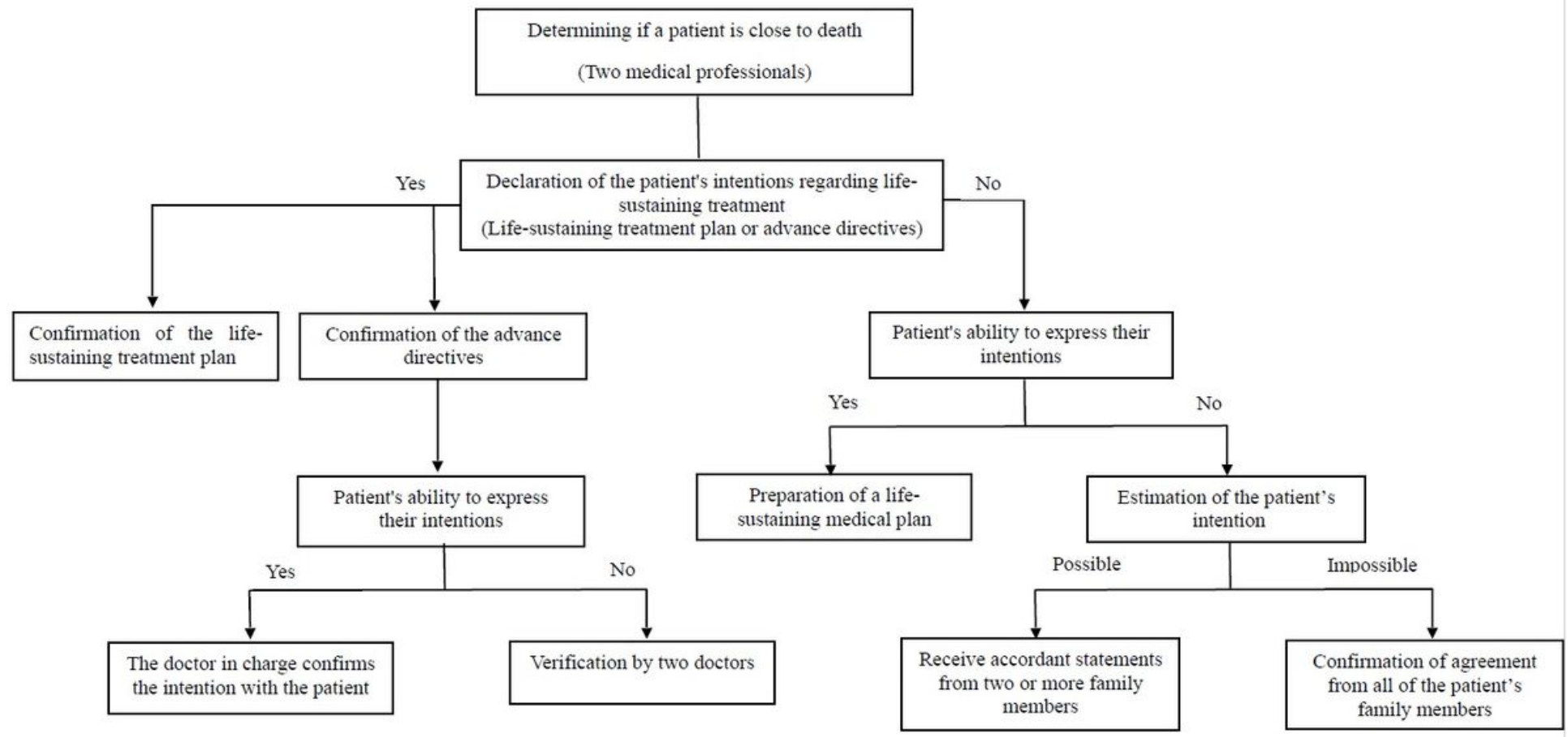

Figure 1

Procedure of decision-making to discontinue life-prolonging care 
Patients over 19 years of age with a diagnosis of stage IV or metastatic cancer who visited the ER during the study period,

$\mathrm{N}=1443$

Before the enforcement of the Life

Extending Medical Decision

February 2017 to January 2018

$$
\mathrm{N}=433
$$

DNR consent form prepared in advance or completed

in the ER

$$
\mathrm{N}=197
$$

\section{Records cannot be verified} due to incomplete data

$\mathrm{N}=2$

Before the enforcement of the Life

Extending Medical Decision $\mathrm{N}=195$

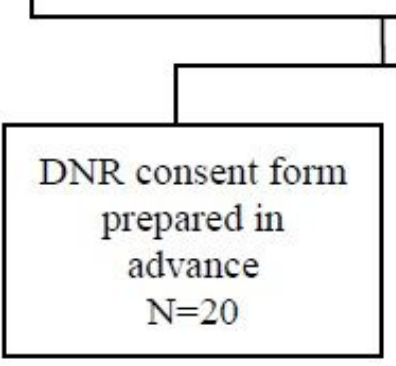

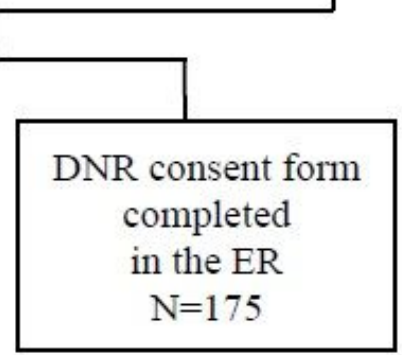

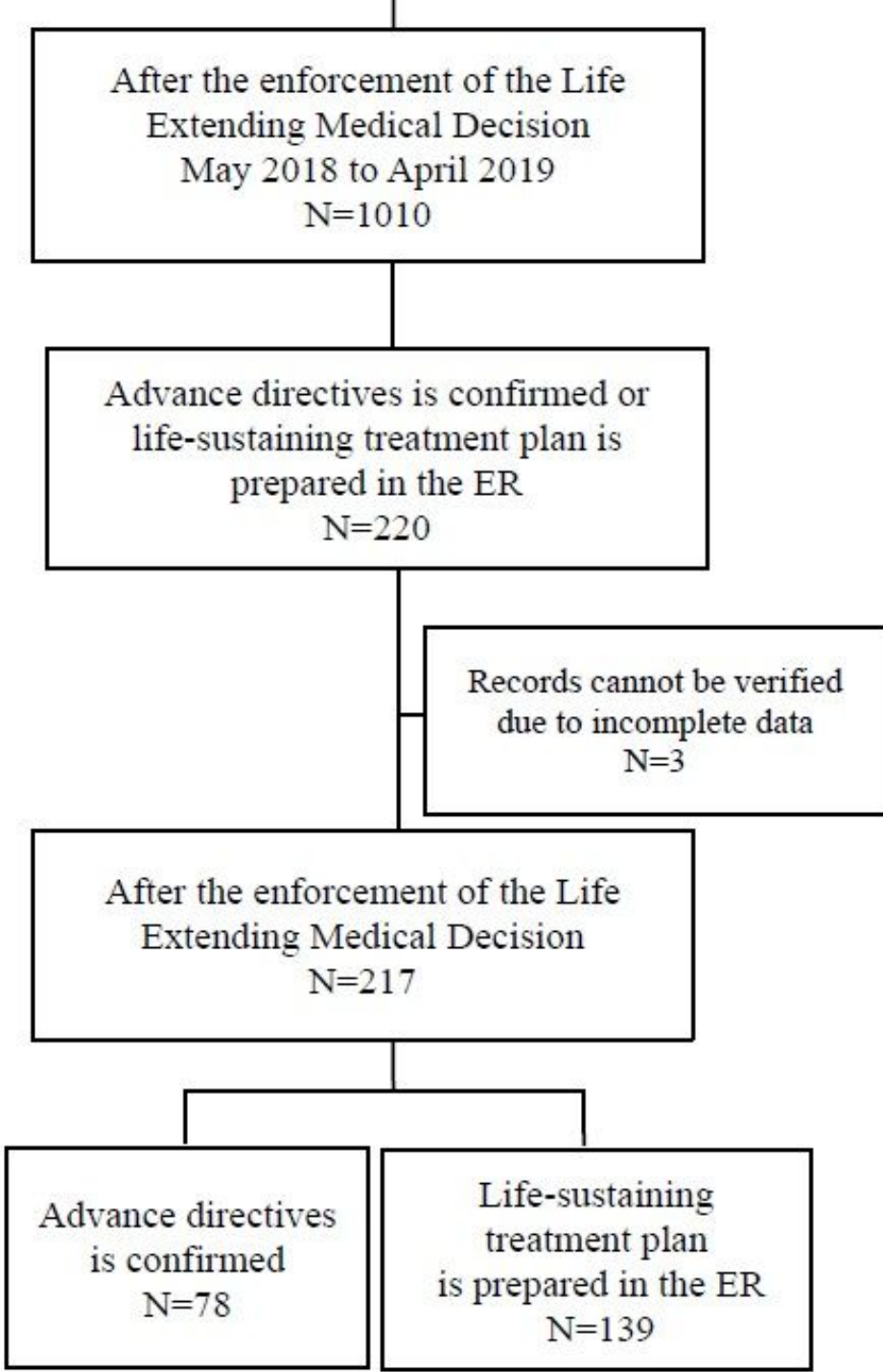

\section{Figure 2}

Flow diagram of patient eligibility. DNR; do-not-resuscitate, ER; emergency room, OPD; outpatient department 